\title{
La Política de la Privatización de las Telecomunicaciones en Brasil*
}

\section{A política da privatização das telecomunicações no Brasil}

MARIA HERMÍNIA TAVARES DE ALMEIDA**

\begin{abstract}
RESUMO: O artigo discute a política das políticas de privatização das telecomunicações no Brasil. Argumenta que suas características resultam de um processo de reforma completamente negociado, explicado pelo cenário institucional que define uma estrutura específica de pontos de veto e pelas concepções predominantes, entre membros da coalizão governante, sobre o papel econômico adequado do Estado. Na primeira parte, são rapidamente apresentadas as condições do setor de telecomunicações anteriores à privatização, a política de privatização e seus resultados. $\mathrm{Na}$ segunda parte, são resumidas as ideias sobre o papel econômico do Estado subjacente ao debate sobre a privatização de empresas estatais. $\mathrm{Na}$ terceira parte, discute o processo político pelo qual a privatização das telecomunicações se concretizou, enfatizando o papel das instituições e dos atores relevantes

PALAVRAS-CHAVE: Privatização; telecomunicações; reforma do Estado; liberalização; regulação.
\end{abstract}

ABSTRACT: The article discusses the politics of telecommunications' privatization policies in Brazil. It argues that its features result from a thoroughly negotiated reform process, explained either by the institutional setting defining a particular veto points structure and by the predominant conceptions, among members of governing coalition, about the proper economic role of the State. In the first part, telecommunications sector's conditions previous to privatization, the privatization policy and its results are rapidly presented. In the second part, the ideas about the economic role of the state underlying the debate about privatization of State-owned enterprises are summarized. In the third part, it discusses the political process

\footnotetext{
* Agradezco a José Expedito Prata, Lidia Goldenstein y muy especialmente a Alejandra Herrera por la paciencia y valiosas informaciones sin las cuales este trabajo no hubiera sido posible. El es parte del proyecto "Las nuevas fronteras del Estado: privatización en perspectiva comparada", apoyado por el CNPq, Proyecto Integrado no 520759/95-8, y FAPESP, Auxílio a Investigación no 96/ 05274-4. Soy grata a los estudiantes Alexandre Sampaio Ferraz, Camila Teodoro, Jamil Chade, Maurício Moya, Wagner Pralon Mancuso y Vanessa Oliveira que forman un equipo de investigación alegre, laborioso y crítico.

* * Departamento de Ciência Política da Universidade de São Paulo - USP, São Paulo/SP. Brasil. E-mail: mariaher@uol.com.br. Orcid: https://orcid.org/0000-0002-9301-9530
} 
through which the privatization of telecommunications came true, stressing the role of institutions and relevant actors.

KEYWORDS: Privatization; telecommunications; State reform; liberalization; regulation. JEL Classification: K23; L33; L96.

Entre 1997 y 1998, el sistema estatal de telecomunicaciones en Brasil fué privatizado, generando U\$ 18,971 mil millones, 51,3\% el valor total obtenido por el Programa Nacional de Desestatización hasta ese momento.

La enajenación de las empresas públicas de telecomunicación es parte de un esfuerzo más amplio de redefinición del rol económico del Estado brasilero, cuyos razgos centrales son: el gradualismo; la negociación política sobre regias, instrumentos y prioridades de las políticas específicas; y el predominio de una visión pragmática, poco ideologizada, acerca de las formas deseables de acción estatal sobre la economía. En otros términos, en Brasil, lo que suele llamarse reforma del Estado, de la cual la privatización de empresas públicas es parte, tardó a empezar, por comparación a los otros países de América Latina; se está procesando de espacio, por medio de engorrosas negociaciones que se dan principalmente el Congreso y consiste en la puesta en marcha de una agenda de reformas orientadas al mercado sin una ideología neoliberal dominante.

En este trabajo sostenemos que las características específicas de la política de privatización de las telecomunicaciones resultan fundamentalmente de la naturaleza negociada del proceso de reformas en curso, del escenario institucional que de fine oportunidades y limitaciones para los actores involucrados y de las concepciones predominantes entre las élites políticas, en el Ejecutivo y la mayoría del Congreso, sobre el nuevo rol del Estado respecto a la vida económica. En la primera parte, describimos brevemente los antecedentes de la decisión de pasar el sistema público de telecomunicaciones a manos privadas, el modelo de privatización y resultados obtenidos. En la segunda parte, discutimos las ideas sobre el rol económico del Estado que enmarcaran el debate sobre la privatización. En la tercera parte, tratamos del juego político de la política de privatización de las telecomunicaciones, o mas precisamente de las instituciones y actores involucrados en el proceso de establecimiento de las regias que definieron el paso del sector a manos privadas.

\section{DEL ESTADO AL MERCADO REGULADO}

El sistema público de telecomunicaciones privatizado en 1997 y 1998 fué obra de los gobiernos militares. La preocupación com el desarollo, la integración y la seguridad nacionales, impulsó la reordenación institucional y la modernización de las telecomunicaciones en Brasil, bajo el régimen autoritário. La meta fué constituir un sistema nacional, conectando las distintas regiones y reduciendo los costos de 
operación. Su instrumento fué la gran empresa pública ${ }^{1}$ En 1965, el gobierno Castelo Branco (1964 -1966) creó la Embratel (Empresa Brasileira de Telecomunicações), encargada de los servicios de larga distancia y radiodifusión, y financiada por el Fundo Nacional de Telecomunicaciones, formado con los recursos de una sobretarifa de $30 \%$ sobre todos os servicios. En esa época se organizó también el Consejo Nacional de Telecomunicaciones (Contel), agencia reguladora y de planificación, vinculada a la Presidencia de la República. La Constitución otorgada de 1967 atribuyó exclusivamente a la Unión el poder de concesión - que hasta el momento era compartido entre ella, los estados y las municipalidades. En el mismo ano, el general Costa e Silva (1967 -1969) constituyó el Ministerio de las Comunicaciones, responsable por la política para el sector. En la administración Médici (1970-1973 ), fué fundada la Telecomunicações Brasileiras S.A. (Telebrás, 1972), empresa holding de las 27 concesionarias públicas - llamadas empresas-polo - que a nivel de los estados eran responsables por los servicios internos de telefonia; y poco después el $\mathrm{CPqD}$ (Centro de Pesquisa e Desenvolvimento), organizado en asociación com dos grandes universidades públicas y volcado a la generación y desarrollo de tecnología transferible a las empresas privadas nacionales de equipos.

La concepción que presidió la organización del sector era desarrollista y estatista. La política que inspiró establecía como objetivos: la operación de redes nacionales de telecomunicaciones, lo que suponía la reestructuración del sistema de franquías conforme a la política establecida; la regulación de la produción de componentes con fuertes incentivos a la sustitución de importaciones ${ }^{2}$; $y$ un esfuerzo deliberado para crear capacidad nacional de investigación y desarrollo que permitiera explorar "oportunidades tecnológicas" (Costa, 1997: 46).

La modernización del sector de telecomunicaciones, bajo la condución de grandes empresas públicas, se há hecho en un marco institucional que confería a estas gran autonomía financiera, administrativa y de decisiones en relación al gobierno ${ }^{4}$. El ejecutivo federal mantenía un único instrumento importante de interferencia en

\footnotetext{
${ }^{1}$ Para una descripción de la política de los militares ver Pastoriza (1996) y Costa (1997). Las informaciones que siguen estan basadas en los dos textos, especialmente en el primero.

${ }^{2}$ El sector privado de equipos y componentes de telecomunicación estaba constituído de dos grupos de empresas: a) grandes multinacionales, como Ericsson, NEC, Siemens; b) empresas nacionales de menor porte, como Promon, Elebra, ABC etc. Los principales instrumentos de política industrial fueron: 1) Portaria 661/75 que establecia regias para la nacionalización de equipos y recomendaba la adoción de centrales CPA; 2) El Certificado de Homologación de la Telebrás, por el cual la empresa analisada habilitaba un equipo a participar de las licitaciones públicas 3) La aplicación de la Ley del Similar Nacional a la indústria; 4) La Portaria 622/78 que definía el concepto de empresa nacional, a la cual se daban ventajas como fornecedora del sistema Telebrás; 5) el establecimiento de índices de nacionalización de los equipos; 6) la política de compras de la empresa que dividia el mercado entre las tres grandes fornecedoras (Ericsson, NEC y Siemens, consorciadas con empresas nacionales); 7) la Ley de reserva de mercado de informática, en los 80 (Pastoriza, 1996: 58-60).

${ }^{3}$ En los 70, el CPqD se dedicó a desarrollar tecnología de microeletrónica, laser, fibras opticas y soft ware para CPAs (Centrais por Programa Armazenado) (Costa, 1997: 56)

${ }^{4}$ El principal instrumento legal fué el Decreto-Ley n ${ }^{\circ} 200$, de 1967 , que promovió la Reforma
} 
la vida de las empresas: el poder de nombrar sus presidentes y directores. De toda manera, en fines de los 70, el sector productivo estatal, incluso el ramo de telecomunicaciones era una "caja negra". La asimetría de información constituía el más importante recurso de poder de los altos dirigentes de las empresas públicas - los "agentes" - frente a su "principal”, el gobierno federal. Ni el Ejecutivo, ni mucho menos el Congreso o la Judicatura tenían instrumentos adequados para controlar las grandes estatales.

Los resultados de la modernización de las telecomunicaciones en los 70 fueron muy significativos. En 1962, Brasil tenía 1,3 millones de teléfonos (1,7 teléfono/100 habitantes) y tan solo 4 ciudades poseían sistemas que les permitiera hacer llamadas de larga distancia. En 1992, la densidad era de 7,8 teléfonos/100 habitantes y había 11,3 millones de terminales instalados y interconectados en una red nacional (Pastoriza, 1996: 49 y 52).

Sin embargo, el modelo de desarrollo que confería un rol protagónico de primera grandeza a la empresa pública pasó a enfrentar vicisitud es crecientes a partir de finales de los anos 70. El control sobre las empresas del Estado se transformó en parte importante de las políticas macroeconómicas destinadas a combatir la inflación en ascenso. Un conjunto de instituciones fue creado para enfrentar el problema específico de las relaciones principal-agente entre el gobierno y sus empresas $^{5}$. Los esfuerzos gubernamentales por someter las estatales y de estas por huir al control prolongaranse por toda la década de los 80 , con resulta dos variables. Mas, a fines del periodo, las empresas públicas habían perdido mucho de la autonomía que disfrutaban en la década anterior.

Habían perdido parcialmente, también, la capacidad e de inversión, como resultado de la manipulación de precios y tarifas con propósitos anti-inflacionarios ${ }^{6}$ y de la herencia de deudas acumuladas en el pasado, cuando fueran estimuladas por el gobierno a hacer préstamos en el exterior para equilibrar la balanza de pagos.

Administrativa (Martins, 1985: 43). Además, una legislación ambigua, producida entre 1967 y 1968, terminó por liberar las empresas públicas del control del Tribunal de Cuentas (Pessanha, 1997: 132-5)

${ }^{5}$ En 1979, fué instituida na Secretaria Especial das Empresas Estatais (SEST) con el propósito de contrlar los gastos de las estatales. La SEST era parte del esfuerzo por establecer un presupuesto consolidado del sector público federal, que incluyera además de la Administración, las empresas públicas y las transferencias directas del Tesoro a las autoridades monetarias. En consecuencia, de la unificación de los presupuestos, las inversiones anuales debieran ser incluidas en el Presupuesto General de La Unión, aprobado por el Congreso, su execución pasó a ser acompañada por Ministerio de Planificación y los gastos revisados por el Tribunal de Cuentas de la Unión.

Además, el Ejecutivo trató, ni siempre con éxito, de controlar la política de remuneraciones de las empresas. Además, el controle de precios y tarifas públicos se tornó un mecanismo usual de política de administración de la inflación. En el presente, las tarifas de telecomunicaciones están bajo control de los Ministerios de Hacienda y de las Comunicaciones. Finalmente, la Constitución de 1988 sometió las empresas públicas a los mismos procedimientos de compras de bienes y servicios característicos de la administración pública, procedimientos detalladamente reglamentados por la Ley de Licitaciones.

${ }^{6}$ La subcorrección de las tarifas y la creciente inefectividad del esquema amplamente utilizado de subsídios cruzados, por el cual los servicios de larga distancia y de valor agregado financiban los servicios locales, influyeran para la caída de los ingresos y de la capacidad de inversión ( Pastoriza, 1996: 55). 
La inversión promedia en el sistema Telebrás pasó de US\$ 3,5 mil millones/ano, entre 1973/79, a US\$2,4 mil millones/ano entre 1980/89, y US\$3,4 mil millones/ ano en el período 1990/95, cuando las proyecciones del mismo gobierno indicaban que sería necesario un promedio anual de US\$ 9,1 mil millones para modernizar el sistema. ${ }^{7}$ De otra parte, en un grado difícil de precisar, la eficiencia administrativa de las grandes empresas públicas parece haber sido perjudicada por la exacerbación de prácticas de patronage, en el período de redemocratización. Los puestos directivos se transformaran en moneda política corriente en las transacciones entre el gobierno y los partidos de su coalición de apoyo, institucionalizando una especie de spoil system de alto nivel que, muchas veces, no tomaba en consideración criterios de capacidad y experiencia profesionales y introducía fuerte discontinuidad administrativa.

El efecto combinado de eses procesos sobre el sector de telecomunicaciones fué un gran retraso en la expansión de los servicios a cargo de las empresas públicas con las consecuencias así resumidas por Pastoriza (1996: 52): “1) baja calidad de los servicios y alto nivel de congestión; 2) dimensión reducida de la red con muchas localidades no servidas; 3 ) costo elevado de los terminales; 4) larga espera para instalación de líneas telefónicas; 5) insuficiente oferta de servicios de valor adicionado". En el momento de la privatización, la Telebrás estimaba en 13,7 millones las personas que esperaban por la instalación de teléfonos fijos y en 6,5 millones los que aguardaban teléfonos celulares (Folha de S. Paulo, 1998: 10).

A comienzos de los 90, el retraso del sistema brasilero de telecomunicaciones ya era reconocido, así como las dificultades que tenían el gobierno y las empresas públicas del sector para superado. Sin embargo, la alternativa de privatización se chocaba con el artículo n 21 de la Constitución de 1988 que establecía el monopolio estatal sobre los "servicios telefónicos, telegráficos, de transmisión de datos y otros servicios públicos de telecomunicaciones". ${ }^{8}$ Por ese motivo, ellos no fueron incluidos en el listado de empresas del Programa Nacional de Desestatización del gobierno Collor de Mello (1990-1992).

La "flexibilización" del monopolio9 estatal sobre las telecomunicaciones fué uno de los hechos en disputa cuando del intento fracasado de revisión constitucional bajo el gobierno de Itamar Franco (1992-1994). La naturaleza controversa del

\footnotetext{
${ }^{7}$ Cuatro eran las fuentes de financiar las inversiones: generación propia; préstamos en el mercado financiero nacional y internacional, auto financiamiento (asinaturas) y recursos fiscales (especialmente los del FNT). Entre 1974/80 os préstamos en el mercado financiero constituían $48 \%$ de los recursos de inversión, el autofinanciamiento $23 \%$, los recursos fiscales $15 \%$ y los generados internamente $14 \%$. A partir de los $80,53 \%$ venian de recursos generados internamente y $26 \%$ del auto financiamiento (Pastoriza, 1996: 54-5).

${ }^{8}$ En realidad, la Constitución establecía la prerrogativa exclusiva de la Unión para "explotar, directamente o mediante concesión a empresas bajo control accionario estatal" dichos servicios (Constituição Brasileira, 1988: 23)

${ }^{9}$ Por flexibilización se entiende la posibilidad que la Unión, que sigue deteniendo el monopolio sobre el sector, pueda conceder su explotación a empresas privadas.
} 
tema de la privatización de empresas públicas y del monopolio estatal sobre una serie de sectores y servicios explica el bajo relieve de esos temas en la campana electoral de Fernando Henrique Cardoso. De todo modo, su programa de gobierno tenía una referencia explícita a la flexibilización del monopolio sobre las telecomunicaciones ${ }^{10}$. El tema entraba así en la agenda del gobierno.

Electo, Cardoso indicó para el Ministerio de las Comunicaciones su íntimo colaborador, principal articulador político y hombre fuerte del nuevo gobierno, el ingeniero Sergio Motta. ${ }^{11}$ Motta asumió el nuevo puesto denunciando lo que consideraba las "tres tragedias" del área de comunicaciones: la "extrema politización" que transformara el sector "en instrumento de acción política, cuando debería promover el desarrollo nacional"; "la escasez de recursos para inversión" y la "falta de coordinación de la Telebrás". No hubo mención a la privatización del sistema, pero si la promesa de ampliar dramáticamente el acceso a los teléfonos celulares y fijos ${ }^{12}$. En su primer ano, el gobierno envió al Congreso una serie de enmendas que flexibilizaban el monopolio estatal sobre las telecomunicaciones, energía eléctrica, gas canalizado y petróleo, de forma a permitir la concesión de explotación de servicios al sector privado. La enmenda $n^{\circ} 8$ fué aprobada aún en agosto de 1995, estableciendo además de la flexibilización de las telecomunicaciones la obligatoriedad de que la legislación específica resultara de proyecto de Ley a ser discutido y aprobado por el Congreso. ${ }^{13}$

Anticipando una tramitación difícil para el proyecto de ley general de telecomunicaciones, el Ministerio de las Comunicaciones separó en dos proyectos de ley distintos las regias que permitieran la creación de servicios privados de telefonía celular y las normas generales para las telecomunicaciones. En el mismo ano, envió al Congreso la "Ley Mínima de las Telecomunicaciones" ${ }^{14}$, que establecía las normas para la telefonia celular privada, servicios limitados, satélites y servicios de

10 El texto decía: "Proponer enmenda a la Constitución para flexiblizar el monopolio de telecomunicaciones, manteniendo la capacidad de la Unión de coordenar inversiones según los intereses nacionales y preservando el rol del sector público en areas estratégicas y en el desarrollo tecnológico del sector" (Cardoso, 1994: 205).

${ }^{11}$ La indicación de Motta no es ajena a la disputa por areas de influencia entre los dos principales partidos de la coalición de gobierno, el PSDB, partido del presidente pero minoritario, y el PFL, el segundo partido más grande del Congreso. Secretario general del PSDB, Motta ocupó un ministerio que desde el gobierno militar venía controlado por el jefe del PFL. Este, por otro lado, siguió controlando el Ministerio de Minas y Energía que tiene el sector eléctrico público federal bajo su jurisdicción.

${ }^{12}$ Hay indicaciones que, en ese momento, el gobierno aún no había decidido por la privatización de las empresas de telecomunicaciones. El equipo de asesores del Ministro de las Comunicaciones estaba dividido en cuanto al tema y el mismo ministro no tenía posición firmada.

${ }^{13}$ Gran parte de la legislación de privatizaciones se originó de "Medida Provisoria" del Ejecutivo. Ese procedimiento es más favorable al Ejecutivo que la utilización del proyecto de ley, con consecuencias políticas importantes como se podrá ver más adelante.

${ }^{14}$ Lei 9.295 de 19.07.96. Ella fué complementada por el Decreto 2.056 de 04.11 .96 que aprobaba las regias del servicio móvil celular y la Portaria 1533 de 04.11.96 que regulaba la explotación del servicio móvil celular. 
valor adicionado y que fué aprobada en siete meses; y el proyecto de Ley General de Telecomunicaciones, aprobado después de casi veinte tres meses de discusión en la Cámara y en el Senado.

La Ley General trataba de garantizar la universalización de los servicios básicos y la competitividad. Atribuía al gobierno funciones esencialmente reguladoras. Para tanto creaba una agencia reguladora independiente - Agencia Nacional de Telecomunicações (ANATEL) - dotada de autonomía administrativa y financiera y de un corpo directivo con mandato fijo, y para la cual se transferían las atribuciones centrales del Ministerio de las Comunicaciones. La Ley no establecía cualquier obligatoriedad de participación directa del Estado en la oferta de los servicios. Sin embargo, trataba de crear garantías para la universalización. Creaba dos tipos de servicios de telecomunicaciones definidos en función de su escopo, sometidos a regímenes diferentes: los de interese colectivo serían prestados en régimen público y los de interese restricto, en régimen público o privado. Los servicios prestados en régimen público, o sea por medio de concesión o permisión, estaban obligados a cumplir metas de universalización y continuidad. En los dos regímenes los servicios podrían ser prestados por empresas privadas o públicas. Abríase así camino a una privatización que, bajo regulación estatal, diera garantías cuanto a la universalización y estableciera competencia en el mercado, evitando la concentración por el lado de la oferta. La Ley creó también dispositivos volcados a dificultar la captura ${ }^{15}$ de la agencia por los intereses a los que debe regular ${ }^{16}$

La política de privatización fué definida posteriormente y trató de dar cuerpo a los añelos de universalización de los servicios y de competición en el mercado entre empresas concesionarias. ${ }^{17}$ EI país fué dividido entres regiones en el interior de las cuales agruparanse en una empresa las prestadoras de servicios en cada estado $^{18}$ pertenecientes a la holding Telebrás, de manera a agregar áreas de mayor y menor atractividad económica. A estas se sumó la Embratel, que operaba los servicios interregionales e internacionales. En el área de actuación de cada una de las cuatro serían abiertas oportunidades de operación inicialmente para más una empresa competidora, llamada "empresa espejo". Mientras las empresas existentes solo podrían explotar los servicios que ya ofrecían y tendrían de comprometerse con metas de expansión fijadas, las "espejos" no sufrirían limitaciones cuanto a

\footnotetext{
${ }^{15}$ Para una discusión sobre la teoría de la captura ver Stigler (1971).

${ }^{16}$ Entre ellos: 1) la prohibición de que los miembros del Consejo Directivo tengan otras actividades profesionales, empresariales, sindicales y político-partidarias a excepción de la enseñanza universitaria; 2) la prohibición de que tengan intereses, directos o indirectos, en empresas relacionadas a las telecomunicaciones; 3 ) cuarentena de un año después del ejercicio del mandato directivo para que exdiretores puedan representar intereses privados frente a la agencia; 4) la prohibición al ex-diretor de utilizar informaciones privilegiadas obtenidas en el ejercicio de funciones directivas en la agencia.

${ }^{17}$ Los instrumentos principales fueran el Plan de Otorgas, el Plan de Universalización, el Plan de Metas y los contratos de concesión de las empresas del sistema Telebrás, todos elaborados ya pela agencia reguladora, ANATEL.

${ }^{18}$ Estas operaban además los servicios intraestatal, interestatal e intraregional.
} 
servicio y región, ni estarían sometidas a metas determinadas. Cada empresa o consorcio interesado en participar del proceso solo podría competir por una de las cuatro empresas en venta. El sistema de duopolio por área vigorará hasta 2003, cuando la competición generalizada en todas las áreas y para todos los servicios será permitida. La privatización de la telefonía fija tuvo inicio con la venta pública de las cuatro empresas estatales. La venta de las “espejos" está todavía en proceso. El marco general de la nueva política de telecomunicaciones viene resumido en el Cuadro I. Y el resultado de la privatización del sistema Telebrás puede ser apreciado en el Cuadro II.

En lo que respecta a la telefonia celular móvil, el país fué dividido en diez áreas, cada una operando también en sistema de duopolio (Banda A y Banda B). La Ley Mínima permitió que se licitara, en 1997, la Banda B a las empresas privadas que deberían operar en cada área. Posteriormente, en conjunto con la telefonía fija, fueron privatizados los servicios de celular a cargo de las empresas públicas del sistema Telebrás. ${ }^{19}$ Se permitió que un mismo consorcio pudiera comprar una empresa de telefonía fija y dos de telefonia celular en areas distintas. El resultado de la privatización de la telefonía celular está resumido en el Cuadro III.

Finalmente, la nueva política de telecomunicaciones basada en la prestación privada de servicios en un escenario competitivo, bajo regulación estatal, incluye también un ensayo de política industrial en nuevas bases. El mismo BNDES que preside el proceso de privatización de empresas públicas creó un programa de apoyo al sector de telecomunicaciones, en el marco una política de inversión y competitividad, con el objetivo de explotar oportunidades de mercado, a nivel interno y internacional. A diferencia de las políticas industriales prevalecientes anteriormente, ella no viene basada en subsidios y/o protección tarifaria indiscriminados que garantizaban un mercado cautivo a los productores internos. Al contrario, la nueva política trató de identificar oportunidades de inversión resultantes de la privatización, estableció en los contratos de concesión clausula de preferencia para empresas instaladas en el país para la venta de equipos de telefonía, promovió la revisión selectiva de tarifas externas, creó una línea de financiamiento en condiciones semejantes a las que son practicadas en el mercado internacional, trató de atraer grandes empresas internacionales y productores nacionales condicionando el apoyo del banco a la exportación de una parte de la producción..$^{20}$ El programa, en sus dos primeros años invirtió US\$ 80 millones. ${ }^{21}$

Resumiendo, la política de telecomunicaciones brasilera, de la cual la privati-

\footnotetext{
${ }^{19}$ Son diez áreas para la Banda B y ocho áreas para la Banda A, una vez que las áreas 1 (región metropolitana de São Paulo) y 2 (São Paulo excluyendo la región metropolitana) estaban bajo control de la Telesp y las áreas 5 (Paraná y Santa Catarina) y 7 (Rio Grande do Sul) formaran la Tele Celular Sul para efectos de la privatización de la Banda A.

${ }^{20}$ Cf. Mendonça de Barros (1998).

${ }^{21}$ La creación del programa siguió la misma pauta descrita por Schneider (199 4) en su estudio sobre las políticas industriales en los años 70. Dependió de las conexiones personales entre el ministro de las Comunicaciones, el secretario do Política Económica del Ministerio de Hacienda y el presidente del
} 


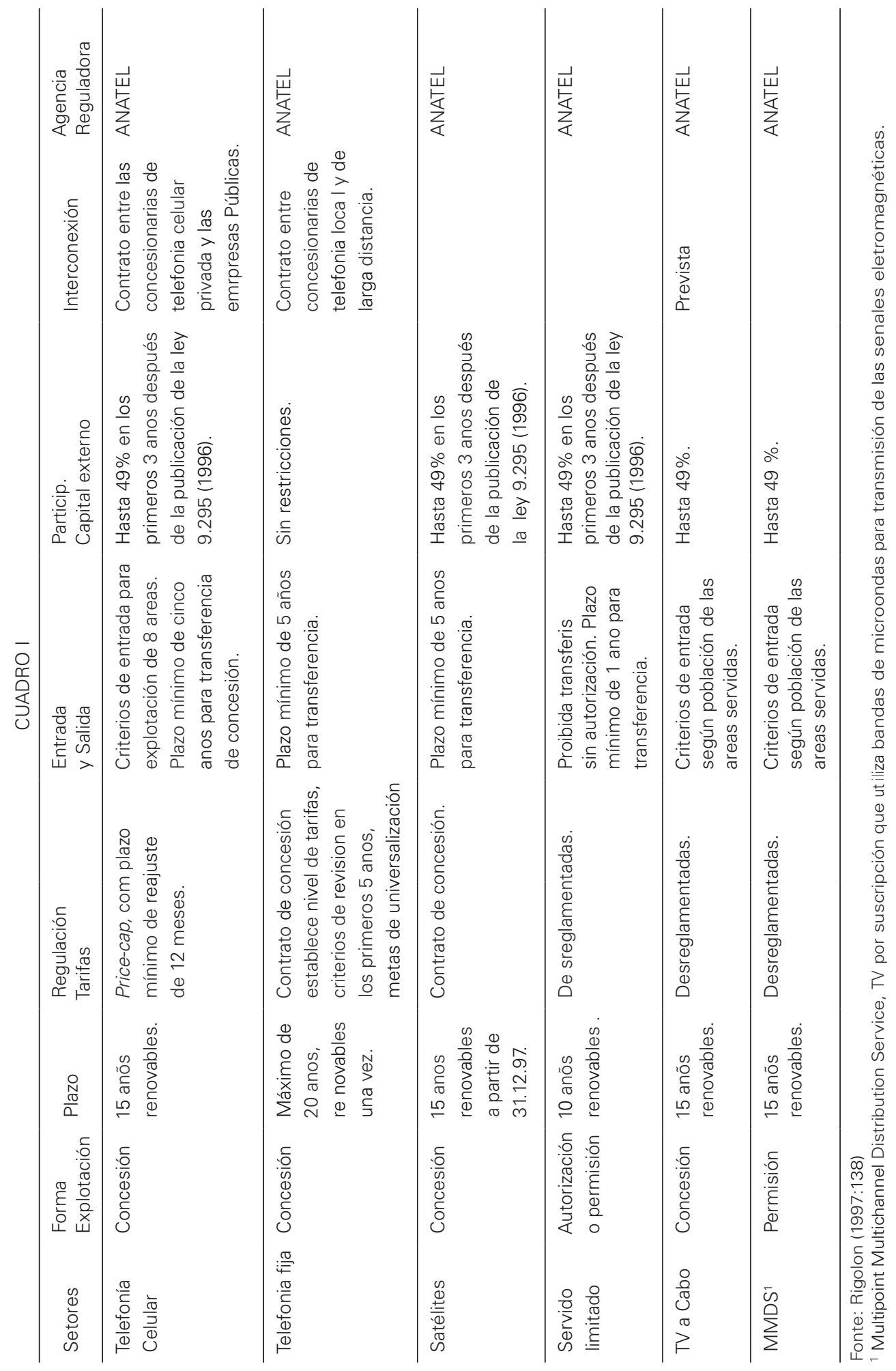




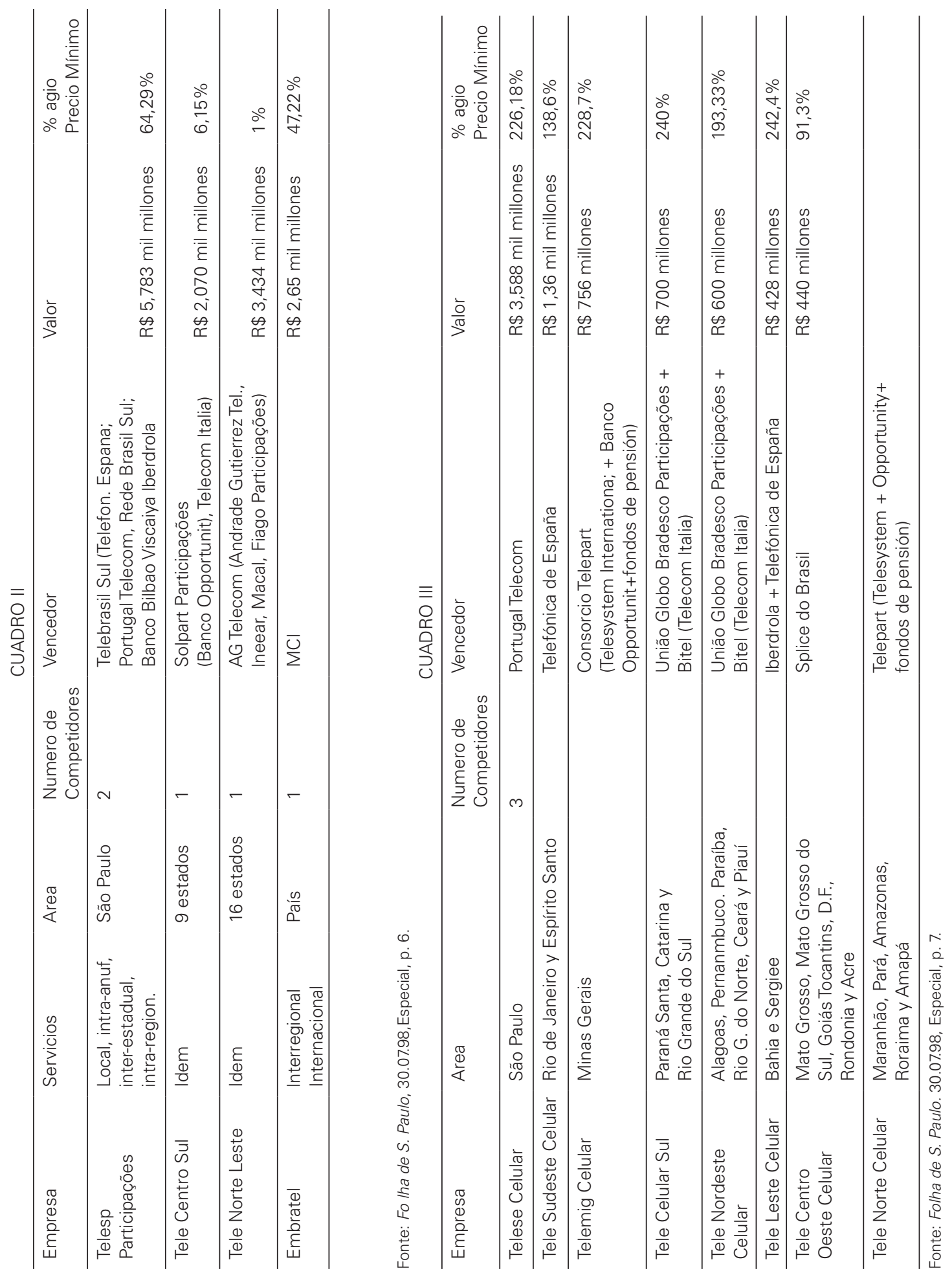


zación constituyó el núcleo duro, definió como metas prioritarias la universalización de los servicios, la defensa del consumidor y, en parte, el apoyo a la industria local, por sobre la maximización del precio de venta y la mantención del control en mano de empresas nacionales ${ }^{22}$. Su desarrollo y resultados dependió de cambios profundos en las concepciones dominantes sobre las relaciones entre Estado y economía, así como del largo proceso de negociación política, cuyo locus principal fué el Congreso.

\section{LA QUIEBRA DEL CONSENSO ESTATISTA}

La política de telecomunicaciones es probablemente la condensación más fiel de las nuevas concepciones sobre el rol del Estado que se fueran gestando en los años 90 y prevalecieron bajo la administración Cardoso. Ella abrió paso en medio a la quiebra lenta, progresiva y difícil del amplísimo y duradero consenso acerca del modelo de sustitución de importaciones y del papel central que en el jugaba el Estado como productor directo y como proveedor de las condiciones institucionales de funcionamiento del mercado protegido.

Como hemos señalado en otro trabajo (Almeida, 1998), la ruptura del consenso estatista implicó en un doble proceso de cambio: en la manera como la opinión pública y los intereses organizados evaluaban el sector público; y en las ideas económicas predominantes entre los policy makers acerca del Estado y de sus empresas.

A fines de los 80, estaba claro que la percepción positiva de la opinión pública cuanto a la eficiencia y la legitimidad de la intervención directa del Estado en la producción de bienes y servicios ya no era unánime y que la retórica anti-intervencionista cundía en diferentes estratos de la sociedad brasileña.

Los cambias eran también significativos a nivel de los policy makers. Ellos resultaban esencialmente del aprendizaje con la experiencia interna de gestión pública bajo la crisis de los 80 , bien como con la observación de lo que ocurría en otros países. Sin embargo, a nivel de las élites decisoras las nuevas ideas sobre el rol económico del Estado pasaban lejos de la ortodoxia neoliberal. Apuntaban hacia un énfasis en las funciones estatales de regulación en un ambiente económico en el cual había que garantizar niveles más elevados de competencia privada. En ese contexto, la privatización de empresas públicas, así como la apertura comercial externa, no eran consideradas cuestiones de principio, pero sí de política práctica. A propósito Cardoso ha declarado:

"Cuando escribimos el programa del PSDB, yo tomé a cargo esta parte [de la reforma del Estado]. Fué durante el gobierno Sarney [1985-1989]. Es-

BNDES, en ausencia de un locus institucionalizado desde donde se proyectara y ejecutara las nuevas políticas industriales.

${ }^{22}$ Esa formulación es de Nassif (1997). 
cribi que nuestro problema no es ni de Estado mínimo, ni de Estado máximo, pero de Estado necesario. Era una manera de salir al paso sin entrar en la ideología. Después, cuando fui Ministro de Hacienda, tuve de enfrentar la cuestión de las privatizaciones. He dicho, por entonces, que para mi esa cuestión no se planteaba como ideología. No se trataba de saber si el Estado es bueno o malo empresario, o si la empresa privada es buena o mala. Hay empresas estatales extremadamente competentes y empresas privadas extremadamente incompetentes. De la misma manera hay corrupción de los dos lados. No se plantea, por lo tanto, en términos de principio, si el Estado es peor o mejor que la empresa, o si el Estado debe de desaparecer. Así, ya antes de tornarme presidente traté de alejar cualquiera connotación meramente ideológica de la cuestión... [Ella] es práctica.” (Toledo, 1998: 288.).

Bresser-Pereira, ministro de Sarney y Cardoso y figura importante en la formulación de las ideas del PSDB, más de una vez ha caracterizado su visión - y del grupo que Cardoso lidera - como un abordaje pragmático de la crisis y reforma del Estado por oposición a las visiones populista y neoliberal. Así resumió sus puntos centrales:

"The pragmatic approach should not be viewed as a rejection of but as an alternative to the Washington consensus, with which it shares many views. Both are opposed to the 'nationalist-populist' posture that still exists in Latin America, although with progressively less credibility and support. The pragmatic approach accepts the need to reduce the since of the state, which has growth exorbitantly in the last fifty years, and agrees that this expansion generated serious distortions, since the state tended to be captured by the special interests of rent seekers. Our approach emphasizes, however, that the crisis of Latin American state is due to exhaustion of the form of state intervention - the import-substitution strategy of development - rather to the sheer size of the state. It does not accept the neoliberal axiom that says, 'since state failures are worse then market failures, the solution is to reduce state intervention to a minimum'. Though state failures may be as bad as market failures, economic reforms and, more broadly, economic policies represent an attempt to limit and overcome these failures. Sometimes reforms imply less state intervention, but sometimes more" (Bresser-Pereira, 1993: 23).

El predominio de un visón pragmático sobre el rol económico del Estado permitió que a lo largo de la discusión sobre la privatización de las empresas públicas diferentes justificativas para su enajenación al sector privado se presentaran y contribuyeran para sumar los intereses y percepciones de distintos actores involucrados en el debate. Los policy makers preocupados con el difícil equilibrio de las cuentas públicas justificaran y saludaran las privatizaciones por los cuantiosos recursos 
adicionales que aportaban. El sector empresarial veía realizados sus reiterados redamos de reducción del rol productivo del Estado y aplaudía las oportunidades de negocios que creaba la venta del patrimonio estatal. Muchos de los altos ejecutivos de las empresas públicas aceptaban por experiencia propia los argumentos que enfatizaban la falta de recursos públicos para inversiones y la excesiva rigidez de reglamentos burocráticos que reducían la flexibilidad de las estatales y su capacidad de competir con las empresas privadas. Los políticos, preocupados con sus electores, eran sensibles sea a las denuncias de rent seeking y de patronage en las estatales, sea a las evidencias de deterioro progresivo de los servicios ofrecidos por los grandes monopolios públicos.

La visión pragmática permitió también que el tema de la regulación de los servicios públicos privatizados ocupara un lugar destacado en la retórica del gobierno, asi como en los proyectos de ley que la administración Cardoso envió al Congreso. El modelo elegido fué lo que los norteamericanos han llamado statutory regulation ${ }^{23}$, o sea, el de la agencia reguladora independiente basada en un mandato legal. ${ }^{24} \mathrm{La}$ independencia frente a las presiones políticas del Ejecutivo, de los partidos o de los congresistas fué la meta central de los policy-makers, percibida como condición para decisiones pautadas por criterios de eficiencia y justicia y protegidas de los conflictos políticos contingentes. Ellos partían de un diagnóstico extremadamente negativo del aparato regulador del periodo anterior ${ }^{25}$, en el que se confundían operación y regulación, y sobretodo trataban de evitar la toma de la agencia sea por la política de patronage, sea por los intereses privados. El discurso de un senador gubernista, durante la discusión del proyecto de la ANATEL, exprime aquella concepción:

"Sería un órgano independiente que no necesitaría que su receta de pendiera de la voluntad política del ministro o del presidente de la República. Órgano a tal punto independiente que sus directivos debieran tener mandato cierto, fijo, solamente demisibles mediante proceso administrativo, por falta grave o por aprobación del Senado al proceso de demisión.

\footnotetext{
${ }^{23}$ Majone (1996: 9-27) distingue la statutory regulation por una agencia independiente y especializada de dos otros tipos de regulación: la regulación por medio de la propiedad pública y la auto-regulación, basada en la delegación de responsabilidades a cuerpos priv ados o semi-privados.

${ }^{24}$ Además de la Anatel, fueran creadas dos otras agencias reguladoras la ANP, para el sector petrolero y la Aneel, para los servicios de energía eléctrica, aunque no se hable de la privatización de la empresa pública de petroleo, la Petrobrás, y que no haya empezado todavía la privatización del sector eléctrico bajo control del gobierno federal, peor tan solo algunas empresas de propiedad de los estados.

${ }^{25}$ El aparato regulador creado en el período del desarrollo bajo dirección del Estado consistía en una variedad de normas y órganos señoriales, creados en diferentes momentos, y afectados a seis grandes áreas sometidas al control del gobierno: 1) la de las empresas públicas proveedoras de bienes y servicios; 2) la de las importaciones; 3) la de la política industrial; 4) la de los precios; 5) la de la defensa de la competencia; 6) la social, incluyendo tanto las relaciones laborales cuanto el medio ambiente y la defensa de los consumidores (Abranches, 1996).
} 
$(\ldots)$

"Por que es importante que ese órgano sea independiente? Porque es un órgano que va a realizar la fiscalización, realizar todo el proyecto de regulación y va a producir las normas que van a estructurar el sector; es un sector que involucra muchos mil millones de dólares, muchos mil millones de reales. Si los directivos de ese órgano no tuvieran autonomía y independencia para poder, muchas veces, interferir contra los intereses de esas empresas, ellos no lo harán, porque tendrán siempre miedo de que las poderosas empresas, por vía de la influencia política, por medio de alguna representación política, puedan amenazarlos de demisión, de ser hechados del cargo, se no atienden a los intereses que están siendo planteados" (Senado Federal, 1997: 13814).

Sin embargo, de la existencia a partir de los 90s de una amplia aceptación de la política de privatizaciones, a nivel de la opinión pública y de élites gubernamentales y políticas, ella fué - y sigue siendo - contestada por una oposición que incluya sindicatos de trabajadores del sector público, partidos y intelectuales de izquierda.

En el caso de la política de telecomunicaciones, la oposición objetó al modelo de privatización con competencia en el mercado, proponiendo sea la pura defensa del monopolio público, sea la creación de un monopolio privado nacional, resultante de la venta de la Eletrobrás entera. La posición privatizante nacionalista fué así expresada:

"El Ministerio de las Comunicaciones y el Congreso Nacional deberían considerar seriamente la racionalidad de también marcharmos para una gran empresa integrada, bajo control nacional, capaz de; 1) negociar parcerias globales; 2) viabilizar el desarrollo de una fuerte base doméstica de producción de equipos y software; 3) acelerar las inversiones, con me tas y compromisos públicamente fijados, para la deseada universalización.

"Si unificadas, las empresas del actual sistema Telebrás (y a ellas sumadas la Embratel), alcanzarían R \$ 8 mil millones de faturamiento, porte suficiente para actuar eficientemente como actor global - especialmente si llevamos en consideración el elevado potencial de crecimiento del mercado brasilero y sud-americano.

"Una gran empresa nacional bajo control privado y gestión profesionalizada de alta calificación - reglada por agencia pública encargada del interés social - podría promover más rápidamente la universalización y, simultáneamente, estimular la producción del país de sistemas, software y equipos, facilitando también nuestro progreso tecnológico" (Coutinho, 1997).

Apesar de la oposición, como se muestra a seguir, hubo una la convergencia amplia entorno al modelo de privatización con competencia y regulación por una agencia independiente. Ella fué producida tras un largo proceso de negociación política. 


\section{EL CAMBIO NEGOCIADO}

Cuando la privatización de las telecomunicaciones entró en la agenda, el proceso de traslado de las empresas públicas al sector privado ya estaba muy avanzado. Habían sido vendidos, en subasta pública, todo el sector siderúrgico y petroquímica estatal, la más grande empresa de mineración de Brasil, parte significativa de las empresas ferrocarrileras y algunas del sector eléctrico de propiedad de estados.

Así, la política de privatización ha seguido el curso de menor resistencia. Empezó por los sectores con relación a los cuales era menor el consenso estatista (Almeida \& Moya, 1997), reduciendo asila posibilidad de surgimiento de poderosas coaliciones de veto.

De otra parte, aunque la iniciativa y concepción de la política vinieran del Ejecutivo, todo el marco legal que definió el curso del proceso tuvo de pasar por el Congreso y ahí fué sometido a discusión sufriendo cambios más o menos importantes.

De todos los sectores hasta ahora incluidos en la política de privatización, el de telecomunicaciones ha sido, probablemente, el que propició la más amplia discusión y negociación en el ámbito del Congreso. Eso ocurrió menos por decisión espontánea del Ejecutivo que por las características del contexto institucional específico en el cual la producción de las reglas de privatización debió ocurrir.

Como se ha señalado anteriormente, la venta de las empresas públicas de telecomunicaciones tuvo de ir por el largo camino de la reforma constitucional y de la reglamentación consecuente por medio de proyecto de ley. Ya la legislación básica de las privatizaciones, que permitió enajenar las empresas siderúrgicas, petroquímicas y ferrocarrileras, pudo ser iniciada por el camino más corto - y más favorable a la rápida aprobación de las propuestas del Ejecutivo - de las "Medidas Provisórias". ${ }^{26}$ En realidad, tanto los procedimientos de reforma constitucional, como, en menor medida, los requeridos para aprobación de proyectos de ley multiplican los puntos de veto (Immergut, 1996 ) 27 y, así, la capacidad de los congresistas de influenciar el resultado final ${ }^{28}$

\footnotetext{
26 "Medidas Provisórias" son iniciativas legislativas del Ejecutivo que entran en vigor de inmediato, debiendo ser debatidas en 30 días, en sesión conjunta del Senado y de la Cámara, que las puede aprobar o rechazar. Las MPs no consideradas en el plazo de un mes pueden ser reeditadas con pequeñas alteraciones. Al vigorar de inmediato, ellas aumentan para los congresistas los costos de su rechazo. Al ser discutidas en sesión conjunta del Congreso, ellas reducen los puntos de veto, facilitando así la tarea de quienes las propusieran.

${ }^{27}$ Debo esa observación acerca de la variabilidad de los puntos de veto, según el tipo tramitación legislativa, a Fabiano dos Santos.

${ }^{28}$ La aprobación de enmenda constitucional requiere quorum cualificado de 3/5 en las dos casas del Congreso, en dos turnos consecutivos. El proyecto de ley requiere mayoría en las dos casas, por separado, y la vuelta del texto a la primera casa, cuando la segunda introduce modificaciones. En los dos casos la tramitación es más compleja y menos favorable a la imposición de los designios del Ejecutivo.
} 


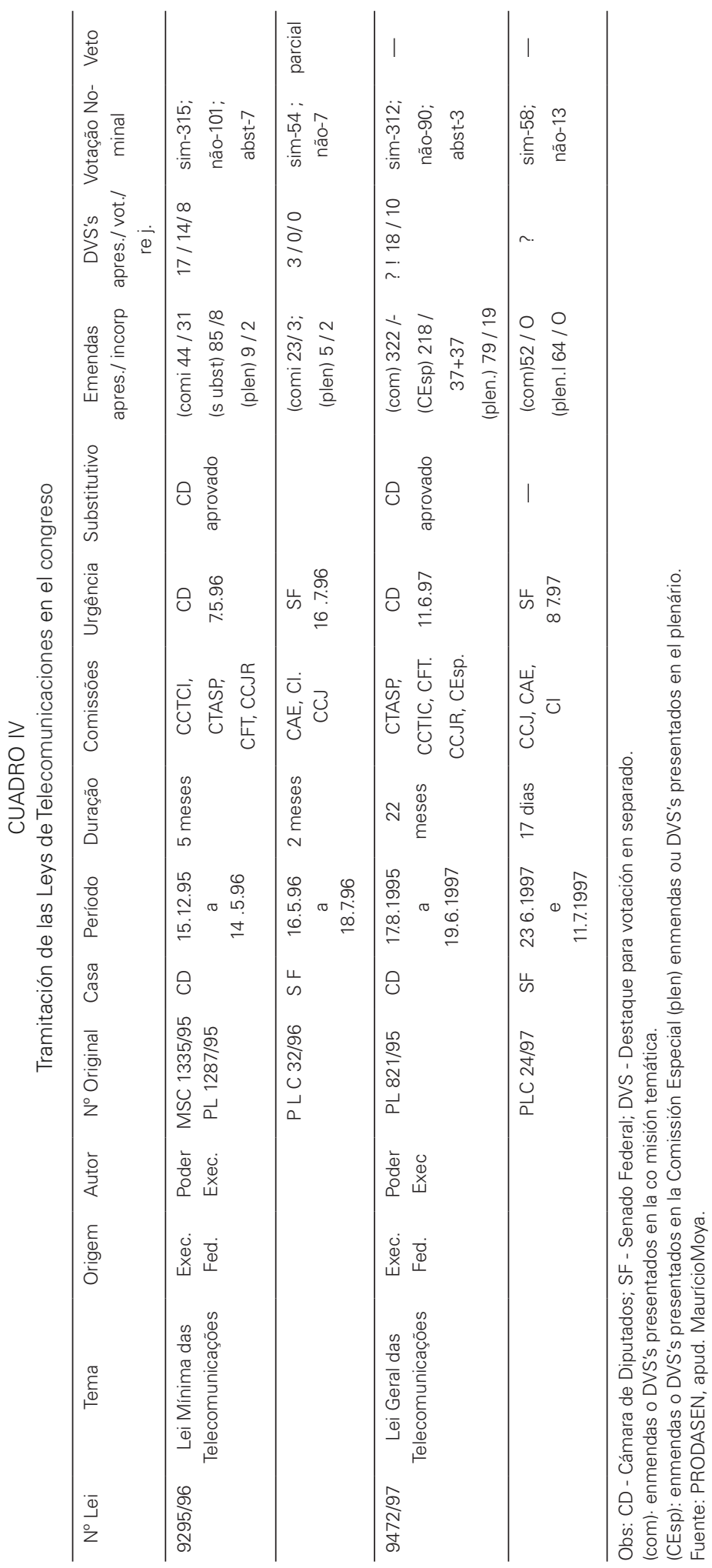


Fué lo que ocurrió sea con el proyecto de Ley Mínima, sea con la Ley General de las Telecomunicaciones, como se puede observar de forma resumida en el Cuadro IV.

La participación del legislativo en la producción del marco legal de las telecomunicaciones puede ser mejor apreciada cuando contrastada con los datos para el conjunto de la legislación que normatiza la política de privatizaciones en Brasil, presentados en el Cuadro V. Como se puede observar, según los criterios ahí establecidos, fueran importantes los cambios introducidos por negociación en el Congreso tanto en la Ley Mínima cuanto en la Ley General. Esa última, vale la pena recordar, se ocupa centralmente del tema de la regulación, definiendo estructura, recursos y atribuciones de la agencia reguladora.

CUADRO V: Partic1pacíon del Congreso en el Cambio de las Proposiciones de Ley*

\begin{tabular}{|c|c|c|c|}
\hline Cambios/ origen proposición & Ejecutivo & Legislativo & Total \\
\hline Ningún cambio ${ }^{\circ}$ & 12 & 0 & 12 \\
\hline Cambio mínimo ${ }^{1}$ & 6 & 0 & 6 \\
\hline Cambio moderado ${ }^{2}$ & 3 & 0 & 3 \\
\hline Cambio importante ${ }^{3}$ & 3 & 2 & 5 \\
\hline Sin información & & o & 1 \\
\hline Total & 25 & 2 & 27 \\
\hline \multicolumn{4}{|c|}{$\begin{array}{l}\text { OBS.: * incluye apenas legislación ya aprobada y sancionada por el presidente. } \\
0 \text { ning una enmenda aprobada rn partes suprimidas por DVS } \\
1 \text { menos de } 5 \text { enmendas aprobadas y/o } 10 \text { partes suprimidas por DVS } \\
25 \text { a } 15 \text { enmendas aprobadas y/o } 10 \text { a } 30 \text { partes suprimidas por DVS } \\
{ }^{3} \text { más de } 15 \text { enmiendas aprobadas y/o más de } 30 \text { partes sup rim idas por DVS } \\
\text { Fue nte: PRODASEN. apud Maurício Moya (1998) }\end{array}$} \\
\hline
\end{tabular}

La aprobación de las normas que permitieron la salida del Estado de la producción directa de servicios de telecomunicaciones - pero no de su regulación - resultó de una distribución de preferencias entre los congresistas que desde hace algún tiempo favorecía la privatización ${ }^{2 \bullet}$ Por esa razón, parte significativa de la discusión en el Congreso estuvo centrada en el tema de la regulación y de la agencia encargada de tornaría efectiva. Muchas de las enmiendas presentadas y aprobadas trataban de tornar más precisos los criterios y dispositivos de control de la actividad privada; de hacer más visible la actividad de la agencia; asegurar el universalismo de procedimientos; definir mejor algunas garantías para las empresas bajo control. En el Senado, tuvo lugar una discusión, importante - aunque sin consecuencias en la legislación - que dividió los partidarios del gobierno y de la privatización acerca del grado de independencia de la agencia vis-a-vis el Congreso ${ }^{30}$.

\footnotetext{
${ }^{29}$ En 1991, tan sólo el 34\% de los congresistas favorecían la participación directa del Estado en las telecomunicaciones. Este porcentaje era más grande entre los partidos de izquierda llegando al $69 \%$ de los parlamentarios del PT y 58\% del PDT (Almeida \& Moya, 1997).

${ }^{30}$ Convicto defensor de la propuesta del Ejecutivo, el senador José Serra (PSDB) fué el vocero de
} 
En síntesis, por medio de una larga y amplia negociación se llegó a producir un nuevo marco legal para el sector de telecomunicaciones que redefine el rol del Estado de productor directo de servicios a regulador de la actividad de los prestadores privados.

La existencia de extensa convergencia en torno a la nueva institucionalidad y al modelo de privatización, que ella permitió y reglamentó, no implicó en que no hubiera oposición al proceso de venta de las empresas y de contestación de su le galidad.

La coalizión de partidos de izquierda, intelectuales y sindicatos de trabajado res y empleados de las empresas en venta organizó protestas públicas tratando de impedir la realización de las subastas en la Bolsa de Valores. Mas, su principal instrumento fué el intento de embargo judicial, por medio de acciones presentadas en distintas partes del país ${ }^{31}$. Aunque no lograran impedir la venta de acciones, tienen los resultados de la privatización hasta hoy bajo contestación y pendientes del juzgamiento por los tribunales.

De otra parte, la actuación del ministro y del presidente del BNDES para estimular la participación de grupos en la privatización y garantizar la existencia de competidores en todas las áreas, tornada pública recientemente, se ha transformado en objeto de controversia y de críticas de la oposición a la legitimidad del proceso.

\section{CONSIDERACIONES FINALES}

La política de telecomunicaciones puesta en marcha trató de evitar la privatización salvaje y de crear condiciones para que el sector privado pudiera proveer servicios de calidad. Sus instrumentos fueran, en primero lugar, un sistema de incentivos fundados en la competición en los mercados y en la vinculación de nuevas oportunidades de mercado al cumplimiento de metas de universalización; y, en segundo lugar, la regulación del mercado por una agencia que se quiere independiente de la política contingente y de la presión de los intereses privados. Incentivos y regulación están inscriptos en el marco legal producido tras mucha negociación.

la defensa de una reducción de la extensión de la delegación a la ANATEL. Aún después de aprobada la Ley, así se expresó: "Hay detalles de la nueva ley que podrán merecer reformulación futura; uno de ellos, sobre el nuevo órgano regulador del sector, debería ser reformulado más rápidamente. Refiero me al nombramiento y destino de los directivos de esa agencia, a fin de que no sea creado en Brasil un nuevo poder, supuestamente por sobre el bien y el mal, sin responsabilidad de responder a las demandas de la sociedad" (Serra, 1997). Ver también Diário do Senado (1997, 13808-09). Sobre el tema de la latitud de la delegación y sobre las condiciones en las cuales el Congreso opta por delegar poder a agencias independientes ver Weingast \& Moran, 1983; Weingast, 1984; Moe, 1997).

${ }^{31}$ La Constitución de 1988 amplió el ámbito de las materias constitucionales y, simultáneamente, los medios a disposición de individuos o organizaciones para protegerse de reales o supuestos actos inconstitucionales. De esa manera, transformó el sistema Judicial en un importante punto de veto, posibilitando una judicialización sin precedentes de los conflictos individuales o colectivos. 
No parece haber discrepancias significativas entre los objetivos añilados y el sistema de incentivos diseñado en ley.

Sin embargo, instituciones son más que normas legales. Para tener eficacia tienen que ser capaces de producir conductas efectivas. En esa medida, dependen tanto de juegos de intereses y de poder, cuanto de representaciones y valores sedimentados.

Además, las nuevas instituciones en creación se enfrentarán a un mercado en rápida mutación y en donde parecen ser fuertes y hondos los impulsos a la concentración. En ese sentido, el perfil futuro de las telecomunicaciones en Brasil depende de la capacidad de anticipación y respuesta en de quienes deberán ejercer control e imponer regias a la actividad privada.

\section{BIBLIOGRAFIA}

ABRANCHES, Sérgio, 1996. "Reforma regulatória e reforma do Estado - conceitos, experiências e recomendações para o Brasil”, texto para discussão, Conselho da Reforma do Estado, MARE, Brasília.

ALMEIDA, Maria Hermínia Tavares de \& MOYA, Maurício, 1997. "A reforma negociada -o Congresso e as privatizações”, Revista Brasileira de Ciências Sociais 12(34), São Paulo, Anpocs, pp. 119. 32.

ALMEIDA, Maria Hermínia Tavares de, 1998. "Reform through negotiation: the privatization of stateowned firms in Brazil”, paper apresentado en LASA - XXI International Congress, Chicago.

BRESSER-PEREIRA, Luiz Carlos, 1993. "Economic reforms and economic growth: efficiency and politics in Latin America “, in: Bresser-Pereira, Luiz Carlos , Maravall, José Màría \& Przeworski, Adam, Economic reforms in new democracies - a social-democratic approach, Cambridge, Cambridge University Press, pp. 15-76.

CARDOSO, Fernando Henrique, 1994. Mãos à obra, Brasil- Proposta de governo, Brasília.

CONSTITUIÇÃO DA REPÚBLICA FEDERATIVA DO BRASIL, 1988. Brasília, Senado Federal, Centro gráfico.

COSTA, Maria Conceição da, 1997. Constrangimentos e mudanças no setor de telecomunicações no Brasil (1979-1995), São Paulo, Tese de Doutoramento apresentada no Departamento de Ciência Política, São Paulo, Universidade de São Paulo.

COUTINHO, Luciano, 1997. "Um projeto para as telecomunicações”, Folha de S. Paulo, 11.05.1997, $2^{\circ}$ caderno.

IMMERGUT, Ellen. 1996. “As regras do jogo: a lógica da política de saúde na França, na Suíça e na Suécia”, Revista Brasileira de Ciências Sociais 11 (30), São Paulo: ANPOCS, pp. 139-66.

FOLHA DE S. PAULO, “Leilão da Telebrás”, Folha de S.Paulo, 30.06.1998: caderno especial.

MAJONE, Giandomenico, 1996. " Regulation and its modes”, Regulati11g Europe, London, Routledge,pp. 9-27.

MARTINS, Luciano, 1985. Estado capitalista e burocracia no Brasil pós 64, Rio de Janeiro, Paz e Terra.

MENDONÇA DE BARROS , Luiz Carlos, 1998. "O BNDES e o novo ciclo de crescimento e desenvolvimento dos complexos industriais de novas tecnologias", $2 \bullet$ versão.

MOE, Terry, 1997. "The positive theory of public bureaucracy”, Mueller, Dennis (ed.). Perspectives on public choice, Cambridge University Press, pp. 455-80.

MOYA, Maurício, 1998. As privatizações e o poder legislativo no Brasil, relatório final de Iniciação Científica PIBIOCNPq, Departamento de Ciência Política, Universidade de São Paulo.

NASSIF, Luiz, 1997. “A polêmica sobre a Telebrás”, Folha de S. Paulo, Caderno 2, p. 3, s.d. 
PASTORIZA, Florinda Ameio, 1996. "Privatização na indústria de telecomunicações: antecedentes e lições para o caso brasileiro”, Textos para Discussão 43, Rio de Janeiro, DEPEC-BNDES.

RIGOLON, Francisco José Zagari, 1997. "Regulação da Infra-estrutura: a experiência recente no Brasil”, Revista do BNDES 4(7), Rio de Janeiro, jun., pp. 123-50.

SENADO FEDERAL, 1997. Diário do Senado Federal, 11.07.1997, Brasília.

SCHNEIDER, Ben Ross,1 994. Burocracia pública e política industrial no Brasil, São Paulo, Editora Sumaré.

STIGLER, George J., 1971, “The theory of economic regulation”, Journal of Economics and Management Sciences, 2, pp. 3-21.

TOLEDO, Roberto Pompeu de, 1998.0 presidente segundo o sociólogo, São Paulo, Cia. das Letras.

WEINGAST, Barry \& Moran, Mark, 1983. "Bureaucratic discretion or Congressional control? Regulatory policy-making by the Federal Trade Commission”, Journal of Political Economy 91: 642-64.

WEINGAST, Barry, 1984. "The Congressional- Bureaucratic system: a principal agent perspective", Public Choice 44: 147-91. 